\title{
Propranolol: Effectiveness and Failure in Infantile Cutaneous Hemangiomas
}

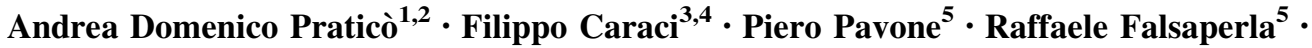 \\ Filippo Drago $^{6} \cdot$ Martino Ruggieri $^{1}$
}

Published online: 9 June 2015

(C) The Author(s) 2015. This article is published with open access at Springerlink.com

\begin{abstract}
Infantile hemangiomas (IHs) occur in early infancy and are considered to be one of the most frequent childhood tumors. Poor responsiveness to the treatment and complications are reported in about $10 \%$ of patients. For years, the most common treatments for cutaneous and complicated IHs were corticosteroids, interferon- $\alpha$, vincristine, laser therapy, or surgical intervention. More recently, treatment with propranolol has been reported with high success rates, both in the cutaneous and complicated form of IHs, and it is now considered to be the first-line treatment for IHs. Herein we report five cases of cutaneous IHs who presented at our unit between January 2011 and June 2012: in three of five patients, the lesion improved soon after the beginning of propranolol treatment; one case presented slow but complete resolution; and in one patient the treatment was unsuccessful. Patients who do not respond to propranolol have been seldom reported in the literature. However, the failure of propranolol treatment in childhood hemangiomas has been more frequent in our
\end{abstract}

Andrea Domenico Praticò

terrenere178@tin.it

1 Department of Clinical and Experimental Medicine, University of Catania, Via S. Sofia 78, Catania, Italy

2 Department of Clinical and Molecular Biomedicine, University of Catania, Catania, Italy

3 Department of Educational Sciences, University of Catania, Catania, Italy

4 IRCCS Associazione Oasi Maria S.S., Institute for Research on Mental Retardation and Brain Aging, Troina, Enna, Italy

5 Unit of Pediatrics and Pediatric Emergency "Costanza Gravina", University-Hospital "Vittorio EmanuelePoliclinic", Catania, Italy

6 Chair of Pharmacology, Department of Clinical and Molecular Biomedicine, University of Catania, Catania, Italy experience than that reported in previous case series. More attention should be given to the cases that poorly or negatively respond to treatment, and to the mechanisms underlying the failure to respond to treatment with propranolol.

\section{Key Points}

Treatment with propranolol has been reported with successful results in the cutaneous and complicated forms of infantile cutaneous hemangiomas and it is now considered to be the first-line treatment for this disorder.

In four of five children treated in our center, propranolol therapy has led to the resolution of the hemangioma, while in one patient it did not give appreciable results.

Worldwide, this therapy does not reach significant results in about $10 \%$ of patients, with re-growth, slow improvement, or failure. The causes of this therapeutic failure have yet to be investigated and further study should be dedicated to this relevant question.

\section{Introduction}

Infantile hemangiomas (IHs) occur with a high frequency in childhood and represent one of the most common tumors of infancy. IHs predominantly affect the female sex, 
caucasians, twins, and premature infants [1]. The lesions may be located in the skin or internal organs, and the most frequent complications are infections and ulceration with necrosis and bleeding.

IHs are located on the face and neck in approximately $60 \%$ of patients, causing severe disfigurement, followed by the trunk $(25 \%)$ and the extremities (15\%) [1]. IHs located in the brain, airways, eye, lumbosacral region, and liver are particularly dangerous because of the risk of complications and difficulties in their treatment [2]. IHs manifest in the first weeks of life, with a rapid proliferative growth that lasts for some months followed by a progressive regression over a period of months or years. Involution occurs completely in $50 \%$ of patients by the age of 5 years and in $90 \%$ by 9 years of age [3].

If localized in the skin, in most cases this condition shows a benign clinical course with complete resolution; conversely, in about $10 \%$ of patients, poor responsiveness to treatment and complications are reported that are related to the size, type, and localization in certain organs, such as the liver, brain, larynx, and small and large intestine [4].

In 1988, we reported a 3-month-old patient with a massive, aggressive mixed hemangioma, localized on right side of the face with ulceration of the ear lobe and nasal septum, associated with cerebral and cerebellar malformations, who died at 4 months of age despite treatment with corticosteroids [5]. Conversely, we have also reported an infant with cutaneous and leptomeningeal diffuse hemangioma who had a rapid and benign course with regression of the lesion in the first year of life [6].

Many types of treatment have been proposed for the cutaneous and complicated forms of IHs-systemic or intralesional corticosteroids, interferon- $\alpha$, vincristine, laser therapy, or surgical intervention-but treatment with propranolol has recently been reported to have successful results in the cutaneous and complicated forms of IHs and it is now considered the first-line treatment for IHs [1, 7-9].

Here, we report on five children affected by cutaneous IHs localized in different areas of the face. In four, treatment with a standard dosage of propranolol resulted in resolution of the lesions. In one, failure to respond to treatment was observed.

\section{Cases Presentation}

Familial and personal histories were carefully recorded for the IH patients and an accurate clinical examination was performed at the beginning of treatment, together with laboratory tests (including complete blood count and coagulation assay), blood pressure, electrocardiogram (ECG) and echocardiogram, abdominal ultrasounds, and in some cases brain magnetic resonance imaging (MRI).
During the treatment, blood pressure evaluation was frequently performed and an ECG and heart ultrasound were carried out every 3 months.

All patients were recruited between January 2011 and June 2012 and started treatment with propranolol (starting dosage $1 \mathrm{mg} / \mathrm{kg} /$ day and rapidly reaching the dose of $2 \mathrm{mg} /$ $\mathrm{kg} / \mathrm{day}$ ) only after parental informed consent. The off-label use of propranolol was proposed to parents according to research published in international peer-reviewed journals [1, 7-9] described in the informed consent and in accordance with Italian legislation [Article 3(2) of Law 94, 1998]. Treatment was continued at home and the child was revaluated after 10 days and then every month.

Dimensions, color, consistency, and photographic documentation based on visual analog scale (VAS) were recorded before and periodically after starting treatment. A minimum $75 \%$ improvement with no regrowth up to 1 month after stopping treatment was considered as success. Propranolol was prepared by the hospital pharmacy as a capsule containing a mixture of propranolol and mannitol.

\section{Case 1}

A 2-month-old girl was referred to our unit with a cavernous non-ulcerated, non-hemorrhagic hemangioma involving the left forehead and the superior part of the nose, measuring $7 \times 4 \mathrm{~cm}$. General conditions were good, and she was breastfed. Treatment with propranolol was started in the following days. Significant reduction in size and discoloration were seen within 2 months. The treatment was stopped at the age of 1 year with resolution of the hemangioma and a small residual scar. At the present time, at the age of 30 months, she does not present recurrence of hemangioma.

\section{Case 2}

A 3-month-old girl came at our unit for observation for a cavernous hemangioma localized in the anterior part of the left forearm, measuring $6 \times 3 \mathrm{~cm}$. Propranolol was started at this age and the girl was treated for a period of 12 months: improvement of the lesion was observed 1 month after the beginning of treatment, initially with a significant discoloration and then with a reduction in size (within 2 months). At the follow-up at 18 months of age, a residual scar surrounded by normal skin was observed.

\section{Case 3}

A 3-week-old boy presented with a facial hemangioma involving the ear lobe and nasal septum. The treatment was started at this age. The initially improvement consisted only in a discoloration, which was noticed after 1 month. The resolution was slow and complete regression of the 
lesion was seen at 15 months of age. At the follow-up at 24 months of age, no regrowth of the lesion was observed.

\section{Case 4}

A 10-month-old girl presented for examination for facial hemangioma localized in the left cheek, measuring $4 \times 2$ $\mathrm{cm}$, which was initially treated at the age of 3 months with prednisone $1 \mathrm{mg} / \mathrm{kg} /$ day. A slight initial improvement was reported and consisted in a minimal, non-significant reduction in the size of the lesion. Therefore, treatment with the corticosteroid was stopped and propranolol was initiated at the age of 4 months. One month later, the girl showed a clearer coloration of the lesion and also a reduction in its size. After 8 months, there was an almost complete resolution of the lesion. At the follow-up at 25 months of age no regrowth of the lesion was observed.

\section{Case 5}

Case 5 was a girl who was the second born of healthy parents, aged 29 and 28 years. Her brother was healthy. No cases of hemangioma were present in the family, and the pregnancy was normal. The girl was born prematurely at 32 weeks of gestation with a birth weight of $1850 \mathrm{~g}$. In the first day of life she presented mild respiratory distress due to the prematurity, and for the first month of life she was placed in an incubator. The presence of a small hemangioma in the middle of the chin was noticed at 6 days of life, and it rapidly enlarged over a period of 2 months. At the age of 3 months, the girl came to our observation. She showed a 'beard hemangioma' involving all of the chin and extending to the lower lips (Fig. 1). The hemangioma caused bleeding, especially during bottle feeding. A dorsal thoracic hemangioma, less relevant in size, was also present. Treatment with propranolol was started at a dosage of $1 \mathrm{mg}$ and then increased to $2 \mathrm{mg} / \mathrm{kg} / \mathrm{day}$. We followed up

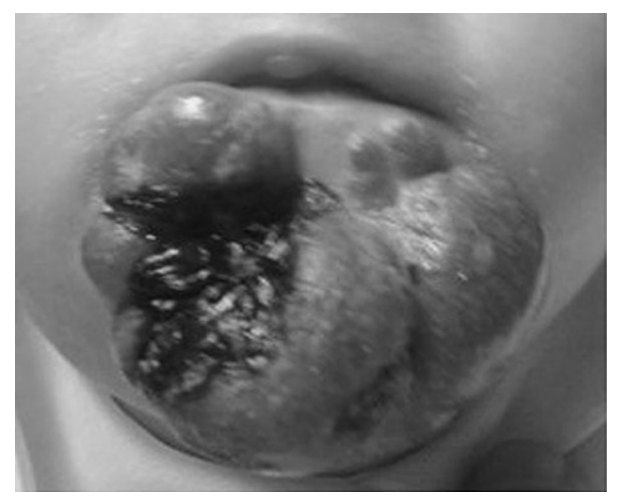

Fig. 1 Patient 5 at 3 months of age: 'beard hemangioma' involving all of the chin and extending to the lower lips. It is possible to notice ulceration that had caused bleeding, especially during bottle feeding the girl every month: in the first month, an improving in the ulcerative lesion and of its bleeding was observed, together with a little discoloration, but after this period, although propranolol treatment was continued, no improvement was observed. At the age of 12 months, when the treatment was stopped, the lesion was still the same size and color as at the beginning of treatment.

At the time of writing, the girl is 19 months old. On physical examination, her general condition is quite good: weight $9 \mathrm{~kg}$ (25th centile), head circumference $46 \mathrm{~cm}$ (25th centile), and height $75 \mathrm{~cm}$ ( 25 th centile). The beard hemangioma is red-vinaceous in color, $7 \times 5 \mathrm{~cm}$ large, presenting a wrinkled surface and involving the chin entirely (Fig. 2). The dorsal thoracic hemangioma is also unmodified. Of note, the girl shows a pre-auricular cutaneous appendix, but no other anomalies are present.

\section{Discussion}

The five patients reported here showed strawberry hemangiomas localized mainly in the face and in one patient on the arm. As reported elsewhere, those of female
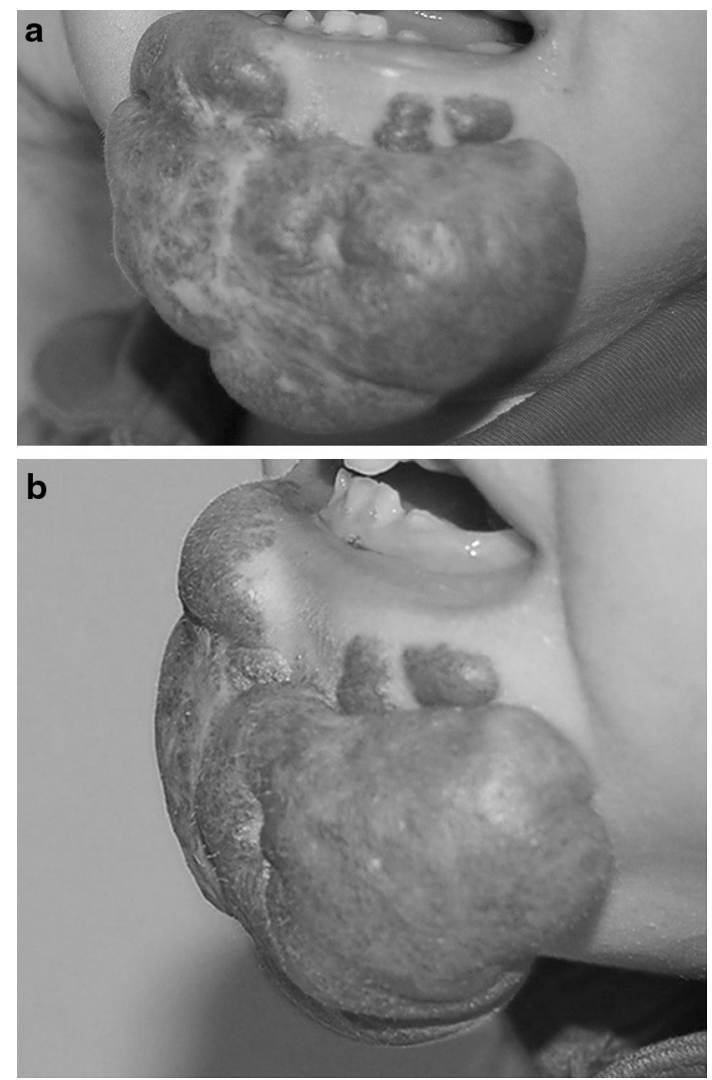

Fig. 2 Patient 5 at 19 months of age: the 'beard hemangioma' is redvinaceous in color, and of the same size as at the start of treatment $(7 \times 5 \mathrm{~cm})$. The hemangioma presents a wrinkled surface and involves entirely the chin 
sex were the most affected with a ratio of $4: 1$. Among these five patients, only one was born prematurely. No positive familial history was reported and no complication during pregnancy was recorded.

In all of the patients, the cutaneous lesion was seen after birth with a rapid growth in the first months of life. The anomalies involved the skin and presented in four of five cases as isolated cutaneous lesions; only patient 5 showed a further localization on their back and a minor malformation consisting of a small pre-auricular cutaneous appendix. In four patients, the treatment was performed with propranolol only. Patient 4 had started treatment with corticosteroids, but propranolol was then employed due a lack of effect. The response to the treatment in our patients was good and rapid in three, slow in one, and unsuccessful in one. This last patient is now a candidate for surgical treatment. No adverse effects were recorded in the children during the period of treatment with propranolol.

The efficacy of propranolol in healing IHs has been well-documented in the literature as single case reports, case series, reviews, and meta-analyses (Table 1) $[8,10-$ 15]. Hemangiomas are made up of various types of cells, including endothelial cells. Capillary endothelial cells are known to express $\beta_{2}$-adrenergic receptors [16] and propranolol is a $\beta$-adrenergic receptor antagonist, initially developed for the treatment of cardiac diseases (angina, infarction, hypertrophic cardiomyopathy, arrhythmias) and hypertension. Propranolol is orally supplied and reaches its peak plasma concentration 1 or $2 \mathrm{~h}$ after intake. Its half-life is 3-6 h, with rapid distribution in the lungs, kidneys, and heart. It is $80-95 \%$ bound to protein and metabolized in the liver [17]. In 2008, Léauté-Labrèze et al. [1] reported the efficacy of propranolol in patients with IHs. Since that year, a large number of studies have reported the efficacy of this treatment in patients affected by IHs, with good tolerance and few adverse effects. The mechanism of action of propranolol in the IHs is not completely understood, but effects on vasoconstriction, a down-regulation of pro-angiogenetic factors such as vascular endothelial growth factor (VEGF) and basic fibroblastic growth factor (bFGF), and stimulation of apoptosis of capillary endothelial cells have been proposed [18-20]. In particular, Zhang et al. [21] have demonstrated that propranolol inhibits the angiogenesis by reducing both VEGF synthesis and release in hemangioma-derived stem cells. In their experimental model, propranolol did not inhibit proliferation or promote apoptosis of hemangioma-derived stem cells isolated from IH patients, but suppressed the expression of VEGF and bFGF in vitro. Morphological, histological, and immunohistological improvement were observed in vivo in murine models. In propranolol pretreated hemangioma stem cells, mean micro-vessel density significantly decreased and protein levels of VEGF markedly decreased, while bFGF was still detectable.

The role of propranolol on the stimulation of apoptosis has been questioned by Kum and Khan [22], in whose experiment propranolol significantly reduced hemangioma stem cell growth but failed to induce the activation of caspase- 3 , which plays a central role in the execution phase of cell apoptosis.

On the contrary, in another study, exposure of hemangioma endothelial cells to propranolol resulted in typical apoptotic morphological changes, including shrinkage, formation of apoptotic bodies, retention of plasma membrane integrity, and, finally, in a marked increase of caspase-8, cytochrome c, apoptosis-inducing factor, caspase-3, and poly (ADP-ribose) polymerase 1 [23]. A recent hypothesis concerns the action of propranolol on the reninangiotensin system (RAS), which may have an important role in the mechanism of action of propranolol [13, 18, 24, 25]. Ultimately, as reported by Ji et al. [26], it is likely that the anti-hemangioma effect of propranolol may not be attributable to a single mechanism, but rather to a combination of events, including pericyte-mediated vasoconstriction, inhibition of vasculogenesis and catecholamineinduced angiogenesis, and the disruption of hemodynamic force-induced cell survival and the RAS.

The adverse effects reported with the use of this drug are usually mild, presenting in most cases as gastrointestinal symptoms, sleep disturbances, and lethargy. Broeks et al. [12], who employed propranolol in the treatment of airways hemangiomas, reported adverse effects in only four of 81 patients: two presented mild gastrointestinal symptoms and two experienced pulmonary symptoms. In the literature, severe adverse effects include hypoglycemic events, hypotension and bradycardia, and bronchospasm and wheezing in asthmatic patients [27-29].

Several studies demonstrate the efficacy of propranolol in the treatment of IHs. A better effect of propranolol than of corticosteroids in the treatment of IHs has been confirmed by the randomized controlled study by Malik et al. [11] in a sample of 30 patients and in a retrospective study by Hermans et al. [15] in 174 patients. In 58 children treated with propranolol at dosage of $1-1.5 \mathrm{mg} / \mathrm{kg} / \mathrm{day}$, Qin et al. [30] reported excellent results in $17.2 \%$, good in $60.4 \%$, moderate in $20.7 \%$, and poor results only in $1.7 \%$. Buckmiller et al. [31] in their experience of 32 patients (dosage $2 \mathrm{mg}$ / $\mathrm{kg}$ /day), reported excellent results in $50,47 \%$ partial responders, and $3 \%$ no responders. Large reviews of propranolol treatment for life-threating airway IHs have been performed by Starkey and Shahidullah [32], Broeks et al. [12], and Lou et al. [13]. Starkey and Shahidullah [32] focused their attention particularly on the adverse effects of propranolol and advise limiting the use of this treatment only 


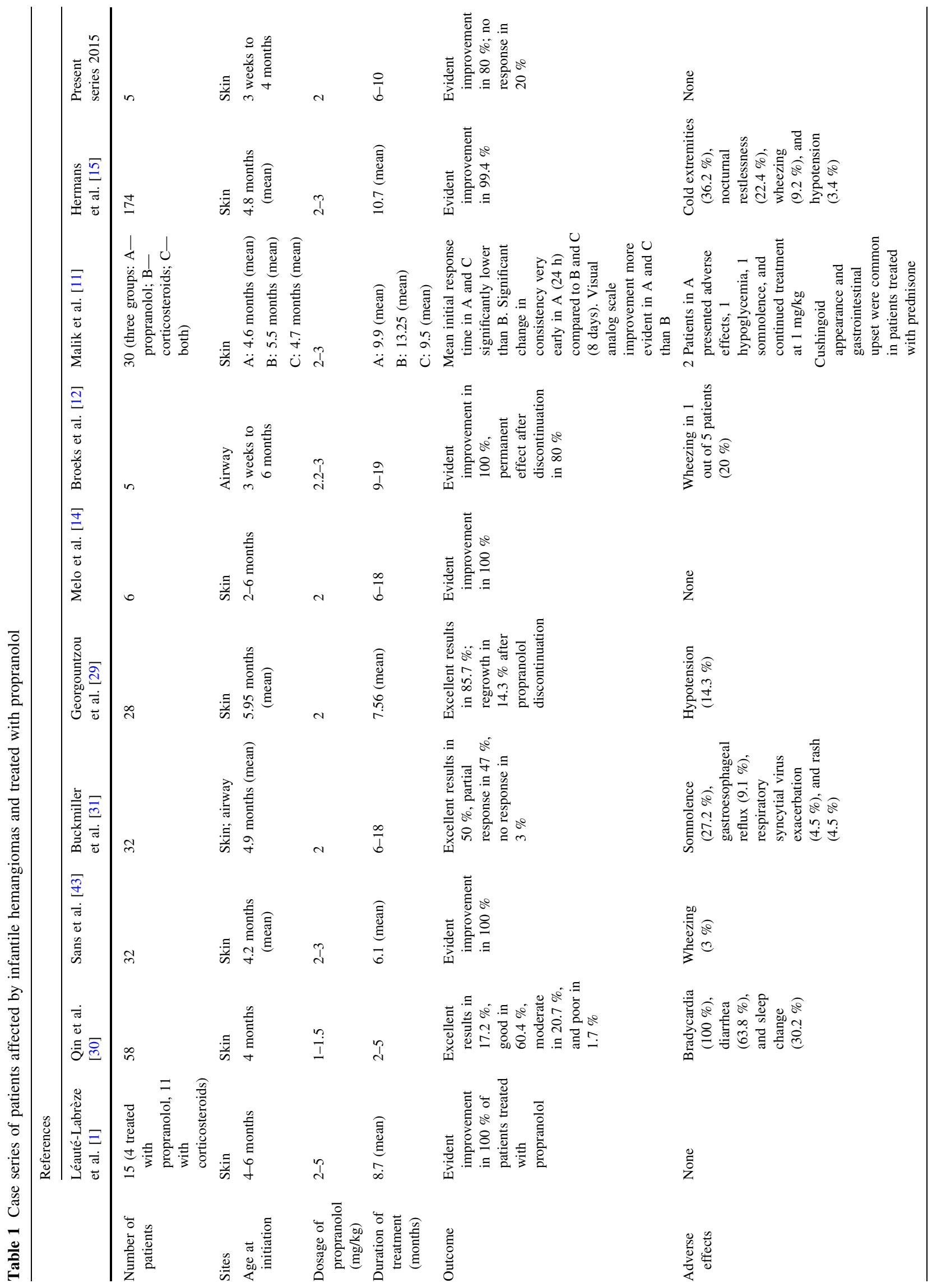


to complicated hemangiomas, underlying that further research should be conducted regarding the safety and efficacy of the treatment. Broeks et al. reported their personal experience in five patients with IHs in the airways treated with propranolol: four had a rapid positive response and only one patient had a relapse of hemangioma with complete resolution after the new cycle of treatment. In their case series and review of the literature involving a total of 81 patients with airway hemangiomas, these authors reported an overall good response in $90 \%$ of the patients. In some nonresponders, dose adjustment or restarting the therapy was effective: only one patient was shown to be resistant to the treatment [12]. In a recent comprehensive meta-analysis, Lou et al. reviewed and compared the results of 35 studies involving 324 patients overall who were affected by IHs. The efficacy of propranolol was higher than the other known treatments such as corticosteroids, vincristine, and laser. Propranolol was more efficacious than the other treatments for all of the types of pediatric hemangiomas (cutaneous, periocular, airway, and hepatic) [13].

Our results confirm the efficacy of propranolol as the gold standard procedure in the treatment of cutaneous IHs, including appreciable aesthetic results with an evident improvement obtained in four out of five patients.

Nevertheless, there are a number (about $9 \%$ ) of $\mathrm{IH}$ patients in whom re-growth, minimal improvement, or treatment failure are reported [12]. Recurrence of IHs after discontinuation of propranolol has been reported by Chang et al. [33] in two children and by Georgountzou et al. [29] in three out of 28 children. Re-growth of IHs has been reported to occur 2-3 weeks after treatment suspension and usually responds to the re-introduction of propranolol [8, $34,35]$. A minimal improvement has been reported in several studies [36-41], but in most of these cases the hemangiomas were localized in internal organs other than the skin or the lesions were particularly wide.

Concerning treatment failure, in a large observational study of 1130 patients treated with propranolol, only ten patients $(0.9 \%)$ did not respond to propranolol and were classified as "propranolol-resistant". The treatment failure was not related to early treatment or to the proliferation stage [42].

The reason for some patients with cutaneous IHs not responding to propranolol is a matter of debate. It is reasonable to presume that ulceration may reduce the effect of propranolol treatment in cutaneous hemangiomas. In fact, in a series of 30 patients with ulcerate hemangiomas, Manunza et al. [20] reported that ten patients with smaller lesions had good results while the patients with deeper ulcerations did not respond to treatment. Conversely, in a patient reported by Malik et al. who had a large scapular hemangioma, treatment with propranolol resulted in interruption of the bleeding in $24 \mathrm{~h}$ and healing of ulcer within 3 months [11]. Excellent results were also obtained by
Melo et al. [14] in a 5-month-old boy with a left arm hemangioma presenting with a lateral ulceration, by Sans et al. [43] in 32 patients where the lesion healed within 2 months, and also by Kim et al. [44] and Naouri et al. [45]. In our patient for whom the treatment failed, the ulceration had a rapid improvement soon after the start of the treatment but the lesion remained unmodified in size and color. Moreover, the therapy did not reduce the lesion on their back, which was not ulcerated.

The reason for the non-responsiveness to propranolol may have other explanations. In some cases, the $\beta$-receptors in affected patients could theoretically be absent or reduced in numbers, thus leading to a non-responsiveness to the drug. Broeks et al. [12] hypothesized a resistance to $\beta$-blockers as the reason for the missed response of some hemangiomas to propranolol. It must be also underlined that poor compliance by the parents may be the reason for the treatment failure in cutaneous hemangiomas.

\section{Conclusions}

To our knowledge, our patient is one of the uncommon cases of cutaneous hemangioma that is non-responsive to propranolol. We presume that the failure of this treatment in cutaneous hemangiomas is more frequent than the rare cases reported in the literature. The excellent effect of propranolol on patients with cutaneous or complicated hemangiomas has been clearly demonstrated, but we believe that more attention should be given to cases that poorly or negatively respond to treatment.

Acknowledgments Written informed consent was obtained from the caregivers of each of the patients for publication of the information and accompanying images included in this case series. A copy of the written consent is available for review by the Editor-in-Chief of this journal.

Andrea Domenico Praticò, Filippo Caraci, Piero Pavone, Raffaele Falsaperla, Filippo Drago, and Martino Ruggieri declare that they have no conflict of interest. No financial support was received for the conduct of this study or preparation of this manuscript.

Open Access This article is distributed under the terms of the Creative Commons Attribution-NonCommercial 4.0 International License (http://creativecommons.org/licenses/by-nc/4.0/), which permits any noncommercial use, distribution, and reproduction in any medium, provided you give appropriate credit to the original author(s) and the source, provide a link to the Creative Commons license, and indicate if changes were made.

\section{References}

1. Léauté-Labrèze C, Dumas de la Roque E, Hubiche T, Boralevi F, Thambo JB, Taïeb A. Propranolol for severe hemangiomas of infancy. N Engl J Med. 2008;358:2649-51. 
2. Schwartz RA, Sidor MI, Musumeci ML, Lin RL, Micali G. Infantile haemangiomas: a challenge in paediatric dermatology. J Eur Acad Dermatol Venereol. 2010;24:631-8.

3. Zimmermann AP, Wiegand S, Werner JA, Eivazi B. Propranolol therapy for infantile haemangiomas: review of the literature. Int $\mathbf{J}$ Pediatr Otorhinolaryngol. 2010;74:338-42.

4. Lin RL, Schwartz RA. Hemangiomas of infancy-a clinical review. Acta Dermatovenerol Croat. 2006;14:109-16.

5. Rizzo R, Micali G, Incorpora G, Parano E, Pavone L. A very aggressive form of facial hemangioma. Pediatr Dermatol. 1988;5:263-5.

6. Falsaperla R, Pavone P, Ruggieri M, Pavone L. Cutaneous and leptomeningeal hemangiomas with impressive benign evolution. Pediatr Neurol. 2013;48:73-5.

7. Zheng JW, Zhang L, Zhou Q, Mai HM, Wang YA, Fan XD, et al. A practical guide to treatment of infantile hemangiomas of the head and neck. Int J Clin Exp Med. 2013;6:851-60.

8. Szychta P, Stewart K, Anderson W. Treatment of infantile haemangiomas with propranolol: clinical guidelines. Plast Reconstr Surg. 2014;134(1):168.

9. Schiestl C, Neuhaus K, Zoller S, Subotic U, Forster-Kuebler I, Michels R, et al. Efficacy and safety of propranolol as first-line treatment for infantile hemangiomas. Eur $\mathrm{J}$ Pediatr. 2011;170:493-501.

10. Denoyelle F, Leboulanger N, Enjolras O, Harris R, Roger G, Garabedian EN. Role of Propranolol in the therapeutic strategy of infantile laryngotracheal hemangioma. Int J Pediatr Otorhinolaryngol. 2009;73:1168-72.

11. Malik MA, Menon P, Rao KL, Samujh R. Effect of propranolol vs prednisolone vs propranolol with prednisolone in the management of infantile hemangioma: a randomized controlled study. J Pediatr Surg. 2013;48:2453-9.

12. Broeks IJ, Hermans DJ, Dassel AC, van der Vleuten CJ, van Beynum IM. Propranolol treatment in life-threatening airway hemangiomas: a case series and review of literature. Int J Pediatr Otorhinolaryngol. 2013;77:1791-800.

13. Lou Y, Peng WJ, Cao Y, Cao DS, Xie J, Li HH. The effectiveness of propranolol in treating infantile hemangiomas: a meta-analysis including 35 studies. Br J Clin Pharmacol. 2014;78:44-57.

14. Melo JN, Rotter A, Rivitti-Machado MC, Oliveira ZN. Propranolol for treatment of infantile hemangiomas. An Bras Dermatol. 2013;88:220-3.

15. Hermans DJ, Bauland CG, Zweegers J, van Beynum IM, van der Vleuten CJ. Propranolol in a case series of 174 patients with complicated infantile haemangioma: indications, safety and future directions. Br J Dermatol. 2013;168:837-43.

16. Iaccarino G, Izzo R, Trimarco V, Cipolletta E, Lanni F, Sorriento $\mathrm{D}$, et al. Beta2-adrenergic receptor polymorphisms and treatmentinduced regression of left ventricular hypertrophy in hypertension. Clin Pharmacol Ther. 2006;80:633-45.

17. Lawley LP, Siegfried E, Todd JL. Propranolol treatment for hemangioma of infancy: risks and recommendations. Pediatr Dermatol. 2009;26:610-4.

18. Storch $\mathrm{CH}$, Hoeger PH. Propranolol for infantile haemangiomas: insights into the molecular mechanisms of action. Br J Dermatol. 2010;163:269-74.

19. Lawley LP, Siegfried E, Todd JL. Propranolol treatment for hemangioma of infancy: risks and recommendations. Pediatr Dermatol. 2009;26:610-4.

20. Manunza F, Syed S, Laguda B, Linward J, Kennedy H, Gholam $\mathrm{K}$, et al. Propranolol for complicated infantile haemangiomas: a case series of 30 infants. Br J Dermatol. 2010;162:466-8.

21. Zhang L, Mai HM, Zheng J, Zheng JW, Wang YA, Qin ZP, et al. Propranolol inhibits angiogenesis via down-regulating the expression of vascular endothelial growth factor in hemangioma derived stem cell. Int J Clin Exp Pathol. 2013;7:48-55.
22. Kum JJ, Khan ZA. Propranolol inhibits growth of hemangiomainitiating cells but does not induce apoptosis. Pediatr Res. 2014;75:381-8.

23. Tu JB, Ma RZ, Dong Q, Jiang F, Hu XY, Li QY, et al. Induction of apoptosis in infantile hemangioma endothelial cells by propranolol. Exp Ther Med. 2013;6:574-8.

24. Zhang L, Mai HM, Zheng J, Zheng JW, Wang YA, Qin ZP, et al. Propranolol inhibits angiogenesis via down-regulating the expression of vascular endothelial growth factor in hemangioma derived stem cell. Int J Clin Exp Pathol. 2013;7:48-55.

25. Kum JJ, Khan ZA. Propranolol inhibits growth of hemangiomainitiating cells but does not induce apoptosis. Pediatr Res. 2014;75:381-8.

26. Ji Y, Chen S, Xu C, Li L, Xiang B. The use of propranolol in the treatment of infantile haemangiomas: an update on potential mechanisms of action. Br J Dermatol. 2015;172:24-32.

27. Breur JM, de Graaf M, Breugem CC, Pasmans SG. Hypoglycemia as a result of propranolol during treatment of infantile hemangioma: a case report. Pediatr Dermatol. 2011;28:169-71.

28. Belson MG, Sullivan K, Geller RJ. Beta-adrenergic antagonist exposures in children. Vet Hum Toxicol. 2001;43:361-5.

29. Georgountzou A, Karavitakis E, Klimentopoulou A, Xaidara A, Kakourou T. Propranolol treatment for severe infantile hemangiomas: a single-centre 3-year experience. Acta Paediatr. 2012;101:e469-74.

30. Qin ZP, Liu XJ, Li KL, Zhou Q, Yang XJ, Zheng JW. Treatment of infantile hemangiomas with low-dose propranolol: evaluation of short-term efficacy and safety. Zhonghua Yi Xue Za Zhi. 2009;89:3130-4.

31. Buckmiller LM, Munson PD, Dyamenahalli U, Dai Y, Richter GT. Propranolol for infantile hemangiomas: early experience at a tertiary vascular anomalies center. Laryngoscope. 2010;120:676-81.

32. Starkey E, Shahidullah H. Propranolol for infantile haemangiomas: a review. Arch Dis Child. 2011;96:890-3.

33. Chang L, Ma G, Jin Y, Ye X, Qiu Y, Chen H, et al. Recurrence of infantile hemangioma after termination of propranolol treatment. Ann Plast Surg. 2014;72:173-5.

34. Holmes WJ, Mishra A, Gorst C, Liew SH. Propranolol as firstline treatment for rapidly proliferating infantile haemangiomas. J Plast Reconstr Aesthet Surg. 2011;64:445-51.

35. Fuchsmann C, Quintal MC, Giguere C, Ayari-Khalfallah S, Guibaud L, Powell J, et al. Propranolol as first-line treatment of head and neck hemangiomas. Arch Otolaryngol Head Neck Surg. 2011;137:471-8.

36. Sierpina DI, Chaudhary HM, Walner DL, Aljadeff G, Dubrow IW. An infantile bronchial hemangioma unresponsive to propranolol therapy: case report and literature review. Arch Otolaryngol Head Neck Surg. 2011;137:517-21.

37. Raol N, Metry D, Edmonds J, Chandy B, Sulek M, Larrier D. Propranolol for the treatment of subglottic hemangiomas. Int $\mathrm{J}$ Pediatr Otorhinolaryngol. 2011;75:1510-4.

38. Javia LR, Zur KB, Jacobs IN. Evolving treatments in the management of laryngotracheal hemangiomas: will propranolol supplant steroids and surgery? Int $\mathrm{J}$ Pediatr Otorhinolaryngol. 2011;75:1450-4.

39. Price CJ, Lattouf C, Baum B, McLeod M, Schachner LA, Duarte AM, et al. Propranolol vs corticosteroids for infantile hemangiomas: a multicenter retrospective analysis. Arch Dermatol. 2011;147:1371-6.

40. Ji Y, Li K, Xiao X, Zheng S, Xu T, Chen S. Effects of propranolol on the proliferation and apoptosis of hemangioma-derived endothelial cells. J Pediatr Surg. 2012;47:2216-23.

41. Canadas KT, Baum ED, Lee S, Ostrower ST. Case report: treatment failure using propranolol for treatment of focal subglottic hemangioma. Int $\mathrm{J}$ Pediatr Otorhinolaryngol. 2010;74:956-8. 
42. Caussé S, Aubert H, Saint-Jean M, Puzenat E, Bursztejn AC, Eschard C, et al. Groupe de Recherche Clinique en Dermatologie Pédiatrique. Propranolol-resistant infantile haemangiomas. $\mathrm{Br} \mathrm{J}$ Dermatol. 2013;169:125-9.

43. Sans V, de la Roque ED, Berge J, Grenier N, Boralevi F, Mazereeuw-Hautier J, et al. Propranolol for severe infantile hemangiomas: follow-up report. Pediatrics. 2009;124:e423-31.
44. Kim LH, Hogeling M, Wargon O, Jiwane A, Adams S. Propranolol: useful therapeutic agent for the treatment of ulcerated infantile hemangiomas. J Pediatr Surg. 2011;46:759-63.

45. Naouri M, Schill T, Maruani A, Bross F, Lorette G, Rossler J. Successful treatment of ulcerated haemangioma with propranolol. J Eur Acad Dermatol Venereol. 2010;24:1109-12. 